\title{
Exploration of Information Flipping Teaching Mode of Interior Design Course Based on the Background of Wisdom City
}

\author{
Hongxing Yi \\ City College of WUST, Wuhan, China \\ 452809105@qq.com
}

Keywords: Intelligent City; Interior Design; Informatization; Flipping Teaching

\begin{abstract}
Based on the intelligent city background, the interior design course also tries to use the information flipping teaching mode to carry on the daily teaching work. Flipping classroom changes the role of teachers and students in traditional teaching by reversing the arrangement of knowledge imparting and knowledge internalization, and reschedule the classroom time. With the development of information technology, information technology builds a personalized learning environment for learners, using mobile phone APP software, such as cloud classes, to combine information teaching methods with reverse classroom teaching methods, and adjust teaching strategies. As far as possible to enhance the effectiveness of the classroom, strive to achieve twice the result with half the effort.
\end{abstract}

\section{Introduction}

At present, the concept of "smart city" is used in the construction of major cities. Intelligent cities use information and communication technology to sense, analyze, and integrate all the key information of the core system of urban operation, thus contributing to the development of public security, including livelihood, environmental protection, and public safety. Urban services, industrial and commercial activities and other needs to make intelligent response. Its essence is to make use of advanced information technology to realize urban intelligent management and operation, and then to create a better life for the people in the city, to promote the harmony and sustainable growth of the city. Based on this background, the daily curriculum teaching in colleges and universities also integrates information teaching into each major curriculum.

In the traditional teaching, teachers teach in the classroom to complete the teaching tasks, and the internalization of knowledge requires students to complete the tasks through homework or operational practice after class. As many of these courses are practical, students may not be able to master all kinds of skills after class through books. In order to change the characteristics of "passivity, dependence, unity and locality" of the traditional teaching methods used in the course, and to highlight the improvement of skills, so as to turn to the "initiative and integrity" of the modern teaching methods. Interactive and problem-oriented "transformation, using cloud classes and other mobile phone APP teaching software, leading students to use the mobile Internet and combined with the university space cloud platform for proactive learning."

\section{Means of Information Teaching}

Information teaching is guided by modern teaching idea, supported by information technology and applied by modern teaching idea. In the information teaching mode, a series of factors, such as concept, organization, content, model, technology, evaluation, environment and so on, are required. At present, in the teaching process, teachers can use video, digital media, micro class, admiration class, flipping classroom, wisdom vocational education focus, class teaching and other auxiliary guiding teaching means to promote teaching and change the former single teaching mode. Abundant learning resources mobilize studentsundefined enthusiasm and initiative, which has positive significance for interior design teaching. 


\section{Exploration of Informationalized Teaching in Interior Design Course}

Informationized teaching in Colleges and universities mainly refers to the modern teaching means based on network and supported by multimedia environment in teaching design and teaching activities. Through the application of information-based teaching methods in the "interior design" course as an example, teachers send course information, pictures, web links, videos, courseware PPT, homework and other teaching resources to students on mobile devices, to organize the discussion of interactive teaching. Team task cooperation, voting questionnaires, Activity Library resources, question-answering discussion and other teaching activities, in the ordinary classroom at any time, live or extracurricular activities at any time, so that at any time network feedback and comments. Teachers immediately release course information, demonstration PPT manuscripts, learning requirements, production of professional videos and other resources to each student's mobile devices, students' mobile devices will become a necessary learning tool to stimulate interest. Real time effective evaluation and tracking of students' learning progress.

Taking the course of Interior Design as an example, teachers mainly use task-driven method, case teaching method and group discussion method to teach. By setting up the teaching process reasonably in the classroom, teachers can make full use of the distributed check-in, questionnaire survey and random classroom selection to consolidate the knowledge in class. After the homework is set up, the group's task is to expand the knowledge after class. Through the mobile terminal information teaching, more than $80 \%$ of students achieve excellent interaction. After a period of information-based teaching curriculum practice, we can see that information-based teaching fully mobilized the enthusiasm of students.

\section{Mobile Learning-Cloud Class and other APP Teaching Software}

Mobile learning relies on mobile phone APP independent development software and university space to achieve information teaching, self-learning means. The application of APP software in cloud classes will lead us to adopt a new learning model under the background of intelligent city and mobile internet era. Now has entered the new era of mobile learning, learning methods are highly fragmented, cloud classes APP application software to solve the problem of learning everywhere. With the rapid development of mobile Internet in the education industry, online education has gradually begun to get rid of the limitations of the Internet and PC, and get a longer tail effect on mobile terminals and peopleundefineds fragmentation time.

APP integrates a series of interactive experiences, such as live video teaching, real-time public screen interaction, instant classroom answers, homework correction after class, social interaction in class circle, and so on, so that learning can be realized anytime and anywhere. In the live video teaching interaction, the students can watch the high quality real-time courseware playing and the teachersundefined interactive pictures with the same content as the PC side online, and the way is very flexible.

In view of the universality of the current Android smart phone system, a teaching model for interior design course is developed by using the APP application software of cloud classes and the university space platform. Nowadays, learning grows up in the era of mobile interconnection, the time of using mobile terminals is much longer than that of using PC, and the interest points are also focused on various mobile interconnection applications. In the application module, the courseware is moved, the video resource is microclass, the work is submitted and the attendance is moved intelligently. All of these are realized by the convenient storage of resources in the university city space and the convenient access to resources of smart phones.

The following objectives were achieved: First, conform to the times and integrate into the trend of mobile Internet. Second, use the model closest to students' life to stimulate students' interest. Third, we should use the university town space to build a micro class resource pool to realize the miniaturization of knowledge courses. Fourthly, it is convenient to acquire, not only the software is realized by scanning two-dimensional code mode, but also the mobile learning of real-time fragmentation under the mobile Internet. 


\section{Integrating Mobile Learning into Flipped Classroom}

By using the teaching mode of flipping classroom, we change the teaching mode from teacher's indoctrination to the mode of self-study, internalization and feedback, so as to improve the learning interest and learning effect. Replanning classroom time, teaching time arrangement flowchart is as follows.(Fig. 1)

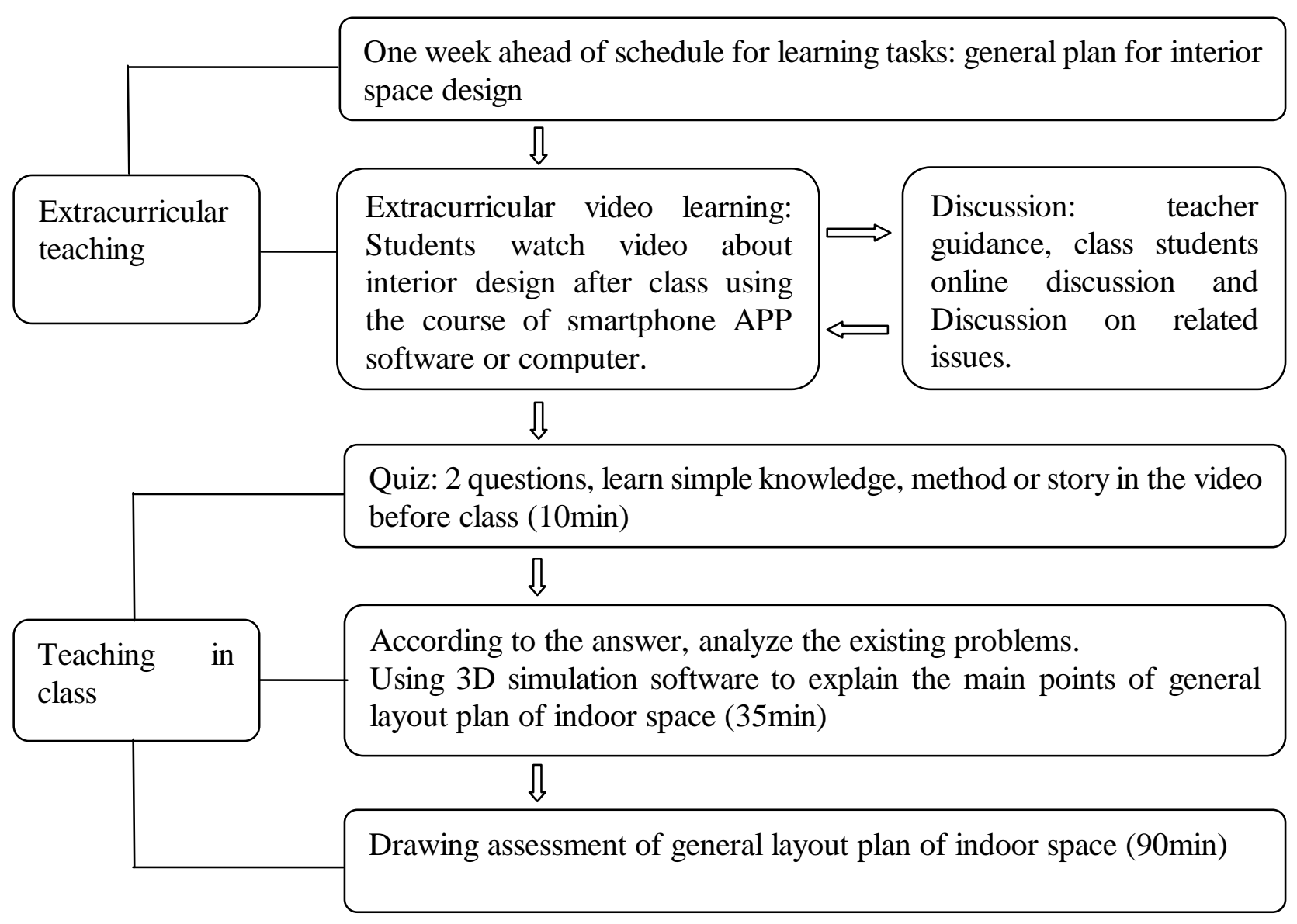

Figure 1. the flowchart of turnover classroom teaching arrangement

1) assign tasks before class. Assign the learning tasks and practice tasks for the next class one week ahead of schedule, and inform the students that the tasks have been published by QQ group and other network methods. Let students focus on the two videos of "interior design drawing method" and "interior design style". In cloud class APP software operation to establish teaching and research room discussion, answer students' questions in time.

2) Start the classroom by asking questions to test the effectiveness of students' micro-lesson learning and to see if they have mastered the main points. Question 1: what is the process of interior design? What are the principles of interior design? Question two: how to express the plan in indoor cartography? What is the standard of drawing? Question three: what are the styles of interior design? Analyze the problems according to students' answers to questions.

3) use 3D simulation software to demonstrate the main points of interior architectural drawing. Through the three-dimensional simulation software to visually display the projection view, especially the sectional view, to enhance students' spatial imagination and improve the drawing accuracy.

4) practice the mapping of general layout of indoor space. Patrol observation to solve the difficult problems of individual students. Through students' off-line learning, teachers comment on key and difficult points in class, submit paper-based homework in class through practical operation, and submit electronic homework in cloud class APP software. Teachers can point out homework problems on the 
spot in class, and also feedback and interaction through APP. Through this way of teaching, students can enhance their confidence in learning and improve their interest in learning.

\section{Prospect of Information Based Teaching Mode}

Teaching mode is a cultural sensitive factor in the education system. New teaching methods and modes can be easily accepted by educators as long as they are truly effective. For our teachers, we are now facing a rapid wave of education informationization. It is very necessary to understand the direction of education reform, update the concept of education, and know how to use modern information technology to support education reform and promote education development.

Entering the information age, the advantages of the information-based teaching model have gradually emerged, and more and more people pay attention to it. We should vigorously develop the information-based teaching model, give full play to the advantages of information technology, make full use of the existing network classroom, campus network, Internet and teaching software, and modify and supplement them so as to make them truly serve teaching and make them go deep into the teaching reform. This will make our educational career more powerful and flourishing.

\section{Summary}

App multimedia teaching software of mobile phone, such as Cloud Class, is a modern teaching method. It has the functions of picture, text, animation and sound. It has the advantages of intuition, dynamic and interactive. It is especially suitable for the teaching of Interior Design. It can fully mobilize the students' initiative, diversified resources and true scene. To enhance students' interest in learning, we can use fragmented time to learn. Flipping classroom teaching mode breaks the traditional teaching mode, students complete knowledge learning at home, and the classroom has become a place for interaction between teachers and students, students and students, including questions and puzzles, the use of knowledge, so as to achieve better educational results.

\section{Acknowledgement}

The research topic of City College of WUST 2018, Exploration and Research on the Teaching Mode of Landscape Design Under the Background of Smart City. Item number:2018CYYCKY013.

\section{References}

[1] L.X. Hu: China Educational Technology, (2012) No.5, p.105.

[2] J.L. Zhang, Y. Wang and H.B. Zhang: Distance Education Journal, (2011) No.5, p.163.

[3] F. Ye: Technology \& Market, Vol. 22 (2015) No.10, p.167-169.

[4] W. Song: Science and Technology Economy, (2017) No.34, p.140.

[5] W.Y. Deng: Journal of Jincheng Institute of Technology, Vol. 8 (2015) No.3, p.58-60.

[6] J. Shi: Journal of Career Academy, Jiamusi, (2017) No.8, p.404-406.

[7] H. Mao: Architectural Planning and Design, (2017) No.9, p.135.

[8] Y.Z. Wang: Brand, (2015) No.3, p.120.

[9] X.L. Wang: China Market, (2015) No.7, p.97-99.

[10] M. Hu and B. Ma: Modern Education Management, (2016) No.1, p.19-24.

[11] Y. Zhang: China Higher Education Research, (2016) No.2, p.70-73.

[12]L. Xu and L.Zhang: Journal of Liaoning Educational Administration Institute, Vol. 26 (2009) No.2, p.33-34. 